'ФГБУ «Национальный медицинский исследовательский центр эндокринологии» Минздрава России, Москва, Россия ФГАОУ ВО «Первый Московский государственный медицинский университет имени И.М. Сеченова» Министерства здравоохранения Российской Федерации, Москва, Россия

Обоснование. В настоящее время активно изучается клеточноопосредованный путь развития сосудистой кальцификации (СК) и взаимосвязь процессов атеросклероза и СК. В некоторых исследованиях показана взаимосвязь циркулирующих остеогенных прогениторных клеток с развитием СК и прогрессированием сердечно-сосудистых заболеваний (СС3), однако не ясна их роль в развитии ССЗ у больных сахарным диабетом 2 типа (СД2).

Цель. Изучить содержание циркулирующих эндотелиальных (CD34+VEGFR2+) и остеогенных (CD34+OCN+) прогениторных клеток у больных ССЗ и СД2.

Материалы и методы. В исследование были включены пациенты с ССЗ (ишемическая болезнь сердца (ИБС) и/или ишемия, угрожающая нижней конечности) с СД2 и без нарушения углеводного обмена. Были сформированы две группы пациентов, первую группу составили лица с СС3 и СД2, вторую - с СС3 без нарушения углеводного обмена. Исследуемые группы были сопоставимы по возрасту, полу, индексу массы тела (ИМТ), статусу курения, показателям липидного обмена, функции почек, ССЗ, проведению реваскуляризации миокарда и нижних конечностей. Пациентам проводился забор периферической венозной крови натощак для определения содержания CD34+OCN+ и CD34+VEGFR2+ прогениторных клеток методом проточной цитометрии. Анализировали 300-500 тысяч событий (клеток) для каждого образца.

Результаты. Всего в исследование был включен 71 пациент (из них 38 женщин, средний возраст 67 лет [62;74]). В 1-ю группу было включено 46 больных (28 женщин), во вторую - 25 (10 женщин).У пациентов с СС 3 и СД2 содержание циркулирующих остеогенных прогениторных клеток статистически было выше, чем эндотелиальных прогениторных клеток $(29,7 \%$ [26,2;36,1] и 11,8\% [9,57;17,2] соответственно, p<0,001). В 1-й группе содержание остеогенных прогениторных клеток было выше, чем во 2-й группе $(29,7[26,2 ; 36,1]$ и 25,6 [17,3;30,7] соответственно; р=0,035). У больных СД2 и СС3 выявлена положительная корреляционная связь количества CD34+остеокальцин+-клеток с уровнем липопротеинов низкой плотности $(r=0,4 ; p=0,032)$ и общего холестерина $(r=0,27 ; p=0,05)$. В 1-й группе пациентов была выявлена положительная корреляция содержания остеогенных прогениторных клеток и индекса SYNTAX Score ( $r=0,50$, p=0,021). У пациентов с CC3 и СД2 была выявлена положительная корреляция CD34+OCN+-kлеток с индексом коронарного кальция ( $r=0,49, \mathrm{p}=0,034)$.

Заключение. Полученные результаты могут свидетельствовать об активном участии остеогенных прогениторных клеток в развитии атеросклеротической кальцификации сосудистой стенки.

КЛЮЧЕВЫЕ СЛОВА: сахарный диабет, атеросклероз, сердечно-сосудистые заболевания, эндотелиальные прогениторные клетки, остеокальцин, ишемическая болезнь сердца, заболевания периферических артерий.

\title{
THE SIGNIFICANCE OF CIRCULATING PROGENITOR CELLS WITH OSTEOGENIC ACTIVITY IN THE ATHEROSCLEROSIS DEVELOPMENT IN PATIENTS WITH TYPE 2 DIABETES MELLITUS
}

(c) Marina S. Michurova ${ }^{1 *}$, Victor Yu. Kalashnikov', Olga M. Smirnova', Svetlana M. Stepanova', Alexander S. Zakharov', Marina V. Shestakova ${ }^{1,2}$, Ivan I. Dedov ${ }^{1,2}$

'Endocrinology Research Centre, Moscow, Russia

II.M. Sechenov First Moscow State Medical University (Sechenov University), Moscow, Russia

Background: There is an interaction between cell-mediated pathway of the vessel calcification and atherosclerosis processes. In some studies the relation between circulating osteogenic progenitor cells and cardiovascular diseases was shown. Though its role in the development of cerebrovascular diseases (CVD) in Type 2 diabetes mellitus (T2DM) remains unknown. Aim: To study the level of circulating endothelial (CD34 + VEGFR2 +) and osteogenic (CD34 + OCN +) progenitor cells in patients with CVD and T2DM.

Methods: We observed patients with CVD (coronary artery disease and / or chronic limb threatening ischemia) with T2DM and without T2DM. Patients with CVD and T2DM were included in group 1 patients with CVD and without T2D were included in group 2. The level of CD34 + VEGFR2 cells and CD34 + OCN+ cells was determined by flow cytometry.There were no differences in the age, gender, lipid profile, body mass index, creatinine clearance, myocardial revascularization and lower limb revascularization between the 2 groups. The level of CD34 + VEGFR2 cells and CD34 + OCN+ cells was determined by flow cytometry. The number of cells was determined by a percentage of the number of CD34+ cells. 
Results: We observed 71 patients (38 women, mean age 67 years $[62,74])$. Forty six patients were included in group 1 (28 women, mean age 68 years [63;75], 25 patients (10 women, 66 years [55;72]) were included in group 2 . We found that in patients with CVD and T2DM demonstrated higher amounts of CD34+OCN+ cells than CD34+VEGFR2+ cells. (29.7\% [26.2;36.1] and $11.8 \%$ [9.57;17.2], $\mathrm{p}<0.001)$. In the 1 st group observed higher amounts of CD34+OCN+ cells, than in the $2 \mathrm{~d}$ group (29.7 [26.2;36.1] и 25.6 [17.3;30.7] соответственно; $\mathrm{p}=0.035)$. Positive correlation was established between amount of CD34+OCN+ cells and atherogenic lipid fraction, $L D L(r=0.4 ; p=0.032)$ and total cholesterol $(r=0.27 ; p=0.05)$ in patients of group 1.While SYNTAX score tertiles and amount of CD34+OCN+ cells ( $r=0.50, p=0.021)$ were the positive correlation. Between coronary artery calcium score and amount of CD34+OCN+ cells $(r=0.49, p=0.034)$ was the positive correlation.

Conclusions: Acquired results may indicate the active role of $\mathrm{CD} 34+\mathrm{OCN}+$ endothelial progenitor cells in atherosclerosis and vascular calcification in patients with T2DM.

KEYWORDS: diabetes, atherosclerosis, cardiovascular diseases, endothelial progenitor cells, osteocalcin, coronary artery disease, peripheral artery disease.

\section{ОБОСНОВАНИЕ}

На протяжении многих десятилетий сахарный диабет (СД) остается независимым фактором риска развития и прогрессирования сердечно-сосудистых заболеваний (СС3). Среди причин смерти и инвалидизации пациентов с СД 2 типа (СД2) СС3 занимают лидирующую позицию. Известно, что у пациентов с СД наблюдается ускоренное развитие и агрессивное течение заболеваний, ассоциированных с атеросклерозом. Наличие у пациентов традиционных факторов риска (курение, артериальная гипертензия, атерогенная дислипидемия, возраст) полностью не объясняет высокую частоту СС3, что заставляет изучать и другие возможные патогенетические механизмы [1].

Установлено, что при СД возрастает интенсивность кальцификации артерий. Так, микрокальцификация атеросклеротической бляшки способствует ее разрыву и развитию атеротромботических осложнений, тогда как медиальная кальцификация повышает жесткость артерий, нарушая регулирование гемодинамики [2, 3]. Механизмы и молекулярные пути развития сосудистой кальцификации (СК) при СД не установлены. Однако в настоящее время активно изучается клеточноопосредованный путь развития CK. Так, Eghbali-Fatourechi G.Z. и соавт. описали циркулирующие клетки-предшественницы остеобластов в периферической крови и впервые предположили, что данные клетки могут участвовать в эктопической кальцификации [4]. В дальнейшем эта гипотеза подтвердилась открытием миелоидных кальцифицирующих клеток и их участием в СК и кальцификации клапанов сердца [5-7]. В экспериментальных работах с клеточной культурой было показано, что циркулирующие клетки предшественницы (CD34+) у пациентов с высоким окрашиванием остеокальцина (OCN) способны образовывать минеральные отложения [8].

Вместе с тем известно, что циркулирующие эндотелиальные прогениторные клетки (ЭПК), выделяемые костным мозгом, являются высокоактивными клетками, способствующими поддержанию целостности эндотелия, его функций и предотвращающих гиперплазию интимы [9]. Однако в ряде исследований показано, что в популяции циркулирующих ЭПК имеются клетки, экспрессирующие OCN и щелочную фосфатазу, принимающие активное участие в кальцификации интимы. Их количество увеличивается пропорционально прогрессированию атеросклероза. У больных СД2 и ишемической болезнью сердца (ИБС) была обнаружена повышенная экспрессия OCN и костной фракции щелочной фосфатазы на CD34+-клетках, при этом наблюдалось снижение экспрессии эндотелиальных маркеров, таких как сосудистый эндотелиальный фактор роста-2 (VEGFR-2) [8-11]. Теоретически, фенотипический сдвиг циркулирующих прогениторных клеток в направлении остеогенного фенотипа клеток может способствовать кальцификации сосудов у больных СД и тем самым - развитию и прогрессированию атеросклеротической кальцификации в ущерб процессам восстановления эндотелия. Данное явление может объяснять высокую частоту СС3 и сердечно-сосудистых событий у больных СД2 [12].

Таким образом, накоплено достаточное количество данных о снижении количества ЭПК, нарушении их функций при СД2. В то же время неясна роль остеогенных циркулирующих прогениторных клеток (CD34+OCN+) в развитии и прогрессировании ССЗ у больных СД2. В литературе встречается несколько определений прогениторных клеток, экспрессирующих OCN: а именно ЭПК с остеогенной активностью, остеогенные прогениторные клетки, остеокальцин-экспрессирующие прогениторные клетки, прокальцифицирующий фенотип циркулирующих эндотелиальных прогениторных клеток.

\section{ЦЕЛЬ}

Изучить содержание циркулирующих эндотелиальных (CD34+VEGFR2+) и остеогенных (CD34+OCN+) прогениторных клеток у больных СС3 с сопутствующим СД2.

\section{МЕТОДЫ}

Дизайн исследования

Было проведено наблюдательное когортное одномоментное одноцентровое исследование.

Критерии соответствия

Критерии включения: возраст 45-80 лет, пациенты с ИБС или критической ишемией нижней конечности.

Критерии исключения: СД не 2 типа; острый коронарный синдром или острое нарушение мозгового кровообращения в течение предыдущих 6 месяцев; эндоваскулярные вмешательства в течение предыдущих 6 месяцев; гемоглобин менее 90 г/л; злокачественные новообразования, гемобластозы; тиреотоксикоз; терминальная стадия почечной или печеночной недостаточности.

Условия проведения

Набор пациентов проводился в ФГБУ «Национальный медицинский центр эндокринологии» Минздрава Рос- 
сии, Москва. В исследование включались пациенты, поступившие в отделение кардиологии, эндоваскулярной и сосудистой хирургии. Обследование пациентов проводилось в условиях стационара.

\section{Продолжительность исследования}

Исследование проводилось с 2016 по 2018 гг.

\section{Описание медицинского вмешательства}

Всем пациентам было проведено стандартное клинико-лабораторное и инструментальное обследование. При сборе анамнеза обращали внимание на такие параметры, как длительность заболевания, отягощенная наследственность по сердечно-сосудистым заболеваниям, курение, физическая активность. Было проведено рутинное лабораторное обследование, которое включало определение липидного профиля (ХС, ЛПНП, ЛПВП, ТГ), уровня глюкозы в плазме крови, гликированного гемоглобина (HbА $)$, креатинина; расчет скорости клубочковой фильтрации.

У пациентов без СД2 скрининг на выявление нарушения углеводного обмена проводился по уровню $\mathrm{HbA}_{1 c}$ и глюкозы плазмы натощак. Состояние углеводного обмена в группе больных СД2 оценивалось по уровню $\mathrm{HbA}_{1 c}$; пациенты были обследованы на наличие микрососудистых заболеваний согласно существующим рекомендациям [13].

Пациентам по показаниям проводилась коронароангиография. Для количественного определения кальция в атеросклеротических бляшках коронарных артерий проводилась компьютерная томография коронарного кальция.

Для определения содержания $\mathrm{CD} 34+\mathrm{OCN}+$ и CD34+VEGFR2+ прогениторных клеток пациентам проводился забор периферической венозной крови натощак.

\section{Основной исход исследования}

Основным исходом исследования явилось оценка содержания циркулирующих прогениторных клеток (CD34+OCN+- и CD34+VEGFR2+-клетки) в сравниваемых группах.

\section{Дополнительные исходы исследования}

Установлена связь между содержанием остеогенных прогениторных клеток с факторами, влияющими на прогрессирование СС3 (атерогенной фракцией липидного спектра, тяжелым поражением коронарных артерий, кальцинозом коронарных артерий).

\section{Анализ в подгруппах}

Пациенты были разделены на две группы, в первую группу были включены пациенты с ССЗ (ИБС и/или угрожающей ишемией нижней конечности) и СД2, во вторую - с ССЗ без нарушения углеводного обмена, сформировавших группу контроля.

\section{Методы регистрации исходов}

Забор периферической венозной крови для определения содержания прогениторных клеток проводился в пробирки 4 мл Vacutainer (K3EDTA); х окрашивание клеток проводилось не позже чем через 2 ч после забора крови в двух аликвотах. Использовались панели моноклональных антител, конъюгированных с флюоресцентными красителями. 1 пробирка: CD34 fitc, igG 1 изотипический контроль PerCP, igG 1 изотипический контроль PE; 2 пробирка: CD 34 fitc, anti- hVEGFR2/ KDRPerCP, anti-OsteocalcinPE. Окрашивание антителами полученных образцов крови проводили согласно протоколу, рекомендованному производителем. Лизис эритроцитов проводили в растворе LysingSolutionlOTest 3 (Beckmancoulter, Франция) в течение 10 минут при комнатной температуре. Суспензию клеток отмывали в фосфатно-солевом буфере. Цитофлюориметрический анализ проводили на приборе FACSCalibur (BectonDickinson, США) с использованием программного обеспечения CellQuest. Анализировали 300-500 тысяч событий (клеток) для каждого образца. Количество клеток определяли в процентах от количества CD34+ клеток.

Расчет скорости клубочковой фильтрации проводился по формуле CKD-EPI (Chronic Kidney Disease Epidemiology Collaboration).

Для оценки тяжести поражения коронарного атеросклероза использовалась шкала SYNTAX Score [14]. Индекс коронарного кальция оценивался по шкале Equivalent Agatston Score [15].

\section{Этическая экспертиза}

Bсе пациенты подписали информированное согласие на участие в исследовании. Протокол исследования одобрен на заседании Этического комитета ФГБУ «Эндокринологический научный центр» от 23 октября 2013 г. (протокол №11).

\section{Статистический анализ}

Принципы расчета размера выборки: предварительного расчета выборки не проводилось.

Методы статистического анализа данных: для статистической обработки материала использовалась программа SPSS Statistics 22 (SPSSInc, США). Данные представлены в виде медианы [25-й; 75-й процентили]. Для описания качественных данных рассчитывали абсолютные (n) и относительные значения (\%). Нормальность распределения проверялась критерием Шапиро-Уилка. Связь между количественными показателями устанавливали, используя непараметрический метод Манна-Уитни. Для анализа связей между категориальными переменными использовали критерий Х-квадрат Пирсона и точный критерий Фишера. Анализ корреляции переменных производился по методу Спирмена. Статистически значимыми считали различия при $\mathrm{p}<0,05$.

\section{РЕЗУЛЬТАТЬ}

Объекты (участники) исследования

В исследование был включен 71 пациент (38 женщин, средний возраст 67 лет [62;74]). Были сформированы две группы, в 1-ю группу были включены 46 больных (28 женщин), во вторую - 25 (10 женщин).

Исследуемые группы были сопоставимы по возрасту, полу, индексу массы тела (ИМТ), статусу курения, показателям липидного обмена, функции почек, СС3, проведению реваскуляризации миокарда и нижних конечностей (табл. 1). 
Таблица 1. Клиническая характеристика пациентов

\begin{tabular}{|c|c|c|c|}
\hline Показатель & $\begin{array}{c}\text { Группа } 1 \\
\text { СС3 и СД2 } \\
(n=46)\end{array}$ & $\begin{array}{c}\text { Группа } 2 \\
\text { CC3 6ез СД2 } \\
(n=25)\end{array}$ & $\mathbf{P}$ \\
\hline Возраст, лет & $68[63 ; 75]$ & $66[55 ; 72]$ & 0,083 \\
\hline $\begin{array}{l}\text { Пол } \\
\text { Женщины, n (\%) } \\
\text { Мужчины, n (\%) }\end{array}$ & $\begin{array}{l}28(60,9) \\
18(39,1)\end{array}$ & $\begin{array}{l}10(40,0) \\
15(60,0)\end{array}$ & $\begin{array}{l}0,172 \\
0,296\end{array}$ \\
\hline Курение, n (\%) & $8(17,4)$ & $6(24,0)$ & 0,598 \\
\hline Индекс массы тела, кг/м²* & $29,4[26,3 ; 34,4]$ & $27,0[26,1 ; 31,2]$ & 0,331 \\
\hline Общий холестерин, ммоль/л* & $4,49[3,52 ; 5,36]$ & $4,51[3,74 ; 4,79]$ & 0,918 \\
\hline ХС лПНП, ммоль/л* & $2,51[1,78 ; 3,32]$ & $2,52[2,13 ; 3,28]$ & 0,621 \\
\hline Креатинин, мкмоль/л* & $74,8[68,5 ; 89,0]$ & $89,1[70,1 ; 99,4]$ & 0,194 \\
\hline Кальций ионизированный, ммоль/л & $1,12[1,09 ; 1,2]$ & $1,10[1,07 ; 1,14]$ & 0,207 \\
\hline $\mathrm{HbA}_{1 c^{\prime}} \%$ & $8,05[6,7 ; 9,2]$ & $5,8[5,5 ; 5,8]$ & 0,0001 \\
\hline ФВ лЖ, \% & $58,0[51,0 ; 62,0]$ & $60,5[55,3 ; 67,0]$ & 0,086 \\
\hline Гипертоническая болезнь, n (\%) & $46(100)$ & $24(94,0)$ & 0,940 \\
\hline Ишемическая болезнь сердца, n (\%) & $32(69,5)$ & $18(72,0)$ & 0,918 \\
\hline $\begin{array}{l}\text { Стенокардия напряжения, n (\%) } \\
2 \text { ФК } \\
3 \text { ФК } \\
4 \text { ФК } \\
\text { Немая ишемия миокарда }\end{array}$ & $\begin{array}{c}9(19,6) \\
10(21,7) \\
2(4,3) \\
6(13,0)\end{array}$ & $\begin{array}{l}7(28,0) \\
4(16,0) \\
- \\
2(8,0)\end{array}$ & 0,642 \\
\hline Инфаркт миокарда в анамнезе, n (\%) & $14(30,4)$ & $10(40,0)$ & 0,416 \\
\hline $\begin{array}{l}\text { Хроническая сердечная недостаточность, } \mathrm{n}(\%) \\
1 \text { ФК } \\
2 \text { ФК } \\
3 \text { ФК }\end{array}$ & $\begin{array}{c}22(47,8) \\
12(26,1) \\
3(6,5)\end{array}$ & $\begin{array}{c}11(44,0) \\
2(8,0) \\
1(4,0)\end{array}$ & 0,096 \\
\hline Ишемия, угрожающая нижней конечности, n (\%) & $12(26,1)$ & $6(24,0)$ & 0,067 \\
\hline Острое нарушение мозгового кровообращения в анамнезе, n (\%) & $7(15,2)$ & $2(8,0)$ & 0,383 \\
\hline Реваскуляризация миокарда, n (\%) & $20(40,3)$ & $10(40,0)$ & 0,825 \\
\hline Реваскуляризация нижних конечностей, n (\%) & $12(26,1)$ & $6(24,0)$ & 0,067 \\
\hline
\end{tabular}

Примечания: *указана медиана (Ме [Q25; Q75]). Тест Манна-Уитни для количественных величин, Хи-квадрат для номинальных величин.

Средняя длительность СД2 оставила 13 [8;21] лет. У 8 пациентов $(17,4 \%)$ была диагностирована непролиферативная диабетическая ретинопатия (ДР), у 3 (6,5\%) препролиферативная ДР, у 3 (6,5\%) - пролиферативная ДР, из них 1 пациенту была проведена лазерная фотокоагуляция сетчатки. Хроническая болезнь почек (ХБП) С2 была выявлена у 11 пациентов (23,9\%), СЗа - у 4 (8,7\%) и С 36 - у 2 (4,3\%).

Пятидесяти пациентам (70,7\%) была проведена коронароангиография по стандартной методике. Остальным пациентам для верификации стресс-индуцированной ишемии миокарда был проведен тредмил-тест (в 1-й группе - 3 (6,6\%) пациентам, во 2-й - 12 (48,0\%)) или стресс-эхокардиография - 3 (6,6\%) пациентам в 1-й группе.

Пациенты обеих групп были сопоставимы по лекарственной терапии на момент включения в исследование (табл. 2). Большинство пациентов получали антиагрегантную и гиполипидемическую терапию. В группе пациентов с СД2 пероральную сахароснижающую терапию
(ПССП) получали 26 пациентов (56,5\%), интенсифицированную схему инсулинотерапии - 10 пациентов (21,7\%). На комбинированной терапии инсулином и ПССП находились 10 пациентов (21,7\%). При поступлении всем пациентам была проведена коррекция гиполипидемической и сахароснижающей терапии.

Основные результаты исследования

1. Анализ результатов исследования эндотелиальных прогениторных клеток и остеогенных прогениторных клеток и ЭПК в исследуемых группах.

У пациентов с ИБС или с ишемией, угрожающей нижней конечности, страдающих СД2, содержание циркулирующих CD34+OCN+-клеток было выше, чем CD34+VEGFR-2+-клеток $(29,7$ [26,2;36,1] и 11,8 [9,57;17,2] соответственно, $\mathrm{p}<0,001$ ) (рис. 1).

Было установлено статистически значимое различие в количестве остеогенных прогениторных клеток в изучаемых группах. Так, в 1-й группе содержание CD34+OCN+-клеток было достоверно выше, 
Таблица 2. Проводимая медикаментозная терапия при поступлении

\begin{tabular}{|c|c|c|c|}
\hline Терапия & $\begin{array}{c}\text { Группа } 1 \\
\text { СС3 и } \\
\text { СД2, n=46 }\end{array}$ & $\begin{array}{c}\text { Группа } 2 \\
\text { СС3 без СД2, } \\
\text { n=25 }\end{array}$ & $\mathbf{p}$ \\
\hline Статины, n (\%) & $32(69,6)$ & $17(68,0)$ & \\
\hline - аторвастатин 10 мг & $5(15,6)$ & $3(17,6)$ & \\
\hline - аторвастатин 20 мг & $14(43,7)$ & $6(35,3)$ & \\
\hline - аторвастатин 40 мг & $3(9,37)$ & $2(11,7)$ & 0,912 \\
\hline - розувастатин 10 мг & $4(12,5)$ & $3(17,6)$ & \\
\hline - розувастатин 20 мг & $4(12,5)$ & $1(5,8)$ & \\
\hline - розувастатин 40 мг & $2(6,25)$ & $2(11,7)$ & \\
\hline Аспирин, n (\%) & $36(78,3)$ & $20(80,0)$ & 0,864 \\
\hline Клопидогрел, n (\%) & $22(47,8)$ & $7(28,0)$ & 0,105 \\
\hline иАПФ/АРА, n (\%) & $37(80,4)$ & $19(76,0)$ & 0,662 \\
\hline $\begin{array}{l}\beta \text {-Адреноблокаторы, } \\
\text { n (\%) }\end{array}$ & $33(71,7)$ & $20(80,0)$ & 0,331 \\
\hline $\begin{array}{l}\text { Антагонисты } \\
\text { кальция, n (\%) }\end{array}$ & $26(56,5)$ & $12(48,0)$ & 0,543 \\
\hline Диуретики, n (\%) & $21(45,7)$ & $7(28,0)$ & 0,215 \\
\hline ПССП, n (\%) & $26(56,5)$ & - & - \\
\hline $\begin{array}{l}\text { Инсулин и ПССП, } \\
\text { n (\%) }\end{array}$ & $10(21,7)$ & - & - \\
\hline $\begin{array}{l}\text { Инсулинотерапия, } \\
\text { n (\%) }\end{array}$ & $10(21,7)$ & - & - \\
\hline
\end{tabular}

чем во 2-й группе $(29,7[26,2 ; 36,1]$ и $25,6[17,3 ; 30,7]$ соответственно, $p=0,035)$ (см. рис. 1).

Кроме того, в группе больных СД2 выявлена статистически значимая положительная корреляционная связь $\mathrm{CD} 34+\mathrm{OCN}+-$ ллеток с коронарным кальцием $(r=0,53$; $\mathrm{p}=0,004)$. Во 2-й группе подобной взаимосвязи не наблюдалось.

2. Связь содержания остеогенных прогениторных клеток с показателями липидного обмена и тяжестью поражения коронарных артерий.

Выявлена положительная корреляционная связь количества CD34+OCN+-клеток с уровнем липопротеинов низкой плотности $(r=0,4 ; p=0,032)$ и общего холестерина $(r=0,27 ; p=0,05)$ (рис. 2) у больных СД2. У пациентов 2-й группы подобной корреляционной связи выявлено не было.

3. Взаимосвязь уровня остеогенных прогениторных клеток с тяжестью поражения коронарных артерий и МСКТ коронарным кальцием

Пациенты в группе с СД2 характеризовались более тяжелым поражением коронарных артерий по шкале SYNTAX Score и высоким индексом коронарного кальция (табл. 3).

В 1-й группе пациентов была выявлена положительная корреляция содержания остеогенных прогениторных клеток и индекса SYNTAX Score $(r=0,50, p=0,021)$. У пациентов с СС3 и СД2 была выявлена положительная корреляция CD34+OCN+-клеток с индексом коронарного кальция $(\mathrm{r}-=-0,49, \mathrm{p}=0,034)$.

Нежелательные явления

В процессе исследования нежелательные явления зарегистрированы не были.

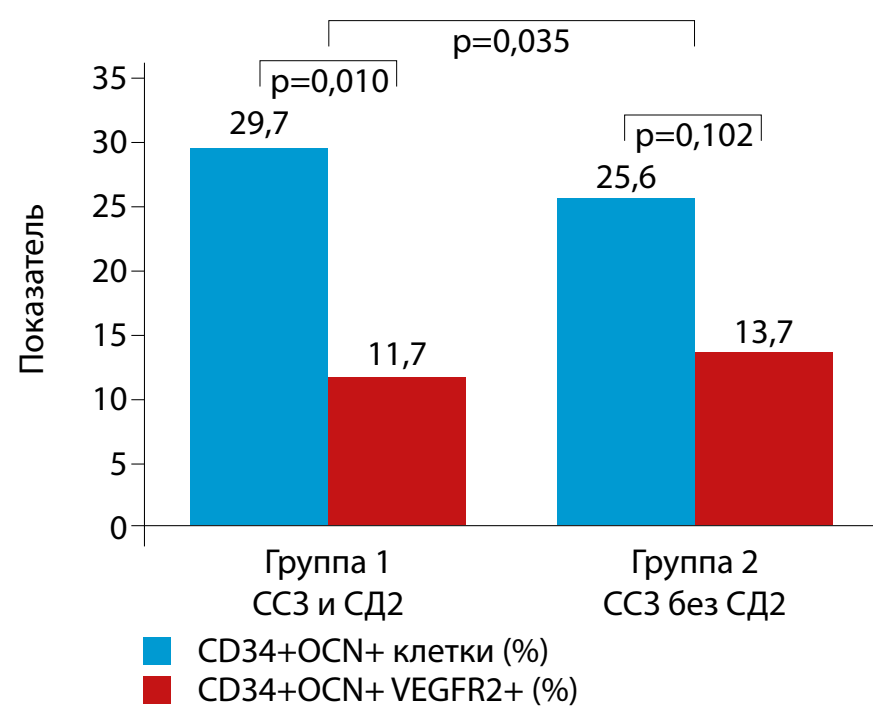

Рис. 1. Циркулирующие прогениторные клетки в исследуемых группах.

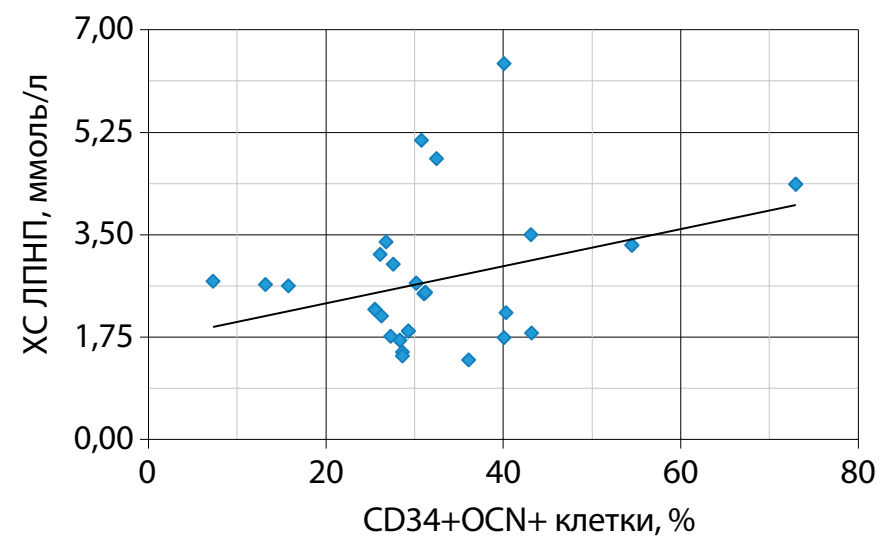

Рис. 2. Корреляция холестерина липопротеинов низкой плотности и содержания CD34+OCN+-клеток у больных СД2.

\section{ОБСУЖДЕНИЕ}

Резюме основного результата исследования

Представленное исследование показало повышенное содержание циркулирующих прогениторных клеток с остеогенной активностью у больных СД2, выявлена связь количества данных клеток с атерогенной фракцией липидного спектра, тяжелым коронарным атеросклерозом, кальцинозом коронарных артерий.

Обсуждение основного результата исследования

Известно, что наличие кальцификации коронарных артерий связано с высоким сердечно-сосудистым риском и является предиктором развития кардиоваскулярных событий [16]. В исследовании было показано,

Таблица 3. Клиническая характеристика пациентов

\begin{tabular}{lccc}
\hline Показатель & $\begin{array}{c}\text { Группа 1 } \\
\text { СС3 } \\
\text { с СД2 } \\
\text { (n=46) }\end{array}$ & $\begin{array}{c}\text { Группа 2 } \\
\text { СС3 } \\
\text { 6ез СД2 } \\
\text { (n=25) }\end{array}$ & p \\
\hline $\begin{array}{l}\text { SYNTAX Score } \\
\text { индекс } \\
\text { Коронарный } \\
\text { кальций }\end{array}$ & $30[17,5 ; 32,0]$ & $14,5[8,75 ; 48,3]$ & 0,04 \\
\hline
\end{tabular}


что у больных с СС3 и СД2 содержание циркулирующих ЭПК (CD34+VEGFR2+-клетки), активно участвующих в восстановлении и поддержании стабильности эндотелия, а также предотвращающих развитие атеросклероза, было снижено, в то время как количество прогениторных клеток с остеогенной активностью (CD34+OCN+-клетки), ассоциированных с развитием и прогрессированием атеросклеротической кальцификации, - повышено. В ранее проведенном исследовании у пациентов с СД2 и ИБС также было выявлено повышение количества CD34+-клеток, экспрессирующих OCN и щелочную фосфатазу [17]. Вероятно, нарушение дифференцировки циркулирующих прогениторных клеток является одним из механизмов прогрессирования сосудистых осложнений, развивающихся при СД2. При этом процессы повреждения сосудистой стенки преобладают над процессами восстановления эндотелия.

Существует гипотеза, что процессы атерогенеза и эктопической кальцификации имеют общую патогенетическую основу, ассоциированную с воспалением. Кальцификация сосудистой стенки наблюдается на ранних стадиях формирования атеросклеротической бляшки [18]. До сих пор ведутся дискуссии, является ли сосудистая кальцификация причиной или следствием атеросклероза. Неоспорим тот факт, что степень кальцификации коронарных артерий является маркером тяжести атеросклероза. Ключевым моментом в инициации сосудистой кальцификации является фенотипическая трансформация резидентных клеток в клетки с остеогенным потенциалом, в число которых входят перициты сосудистой стенки, мезенхимальные стволовые клетки и циркулирующие прогениторные клетки [19]. Развивающиеся при СД2 воспаление, инсулинорезистентность, окислительный стресс могут влиять на реализацию остеогенного потенциала данных клеток. Провоспалительные, атерогенные факторы, продукты оксидативного стресса способствуют остеогенной трансформации клеток-мишеней, способных продуцировать гидроксиапатит, который включается в эктопические преципитаты. Кальцификация интимы формируется либо локально в виде точечной (пятнистой) кальцификации, либо диффузно в виде «листовой» кальцификации. Считается, что атеросклеротические бляшки с «пятнистой» кальцификацией более подвержены разрыву и развитию атеротромботических осложнений. В то время как «листовая» или диффузная кальцификация ассоциируется с бляшками, менее склонными к разрыву [20-22]. В данном исследовании мы выявили положительную корреляцию уровней общего холестерина и атерогенной фракции липидного спектра с содержанием остеогенных прогениторных клеток. Обнаруженный факт может указывать на активное участие данных клеток в процессах атеросклеротической кальцификации в данной когорте больных и еще раз показывает тесную взаимосвязь процессов атеросклероза и сосудистой кальцификации. Наши данные позволили также выявить связь количества остеогенных прогениторных клеток с тяжестью коронарного атеросклероза и васкулярной кальцификацией. Показана положительная корреляция количества CD34+OCN+-клеток с тяжелым поражением и кальцинозом коронарных артерий. Аналогичные результаты были получены в ранее опубликованном исследовании [8], где было показано, что у пациентов с атеросклерозом коронарных артерий был выявлен высокий процент содержания в крови остеогенных ЭПК.

\section{Ограничения исследования}

Малый объем исследуемой выборки не позволяет экстраполировать результаты на всю популяцию больных СС3 и СД2. Одномоментный дизайн не позволяет достоверно судить о причинно-следственных взаимосвязях между признаками.

\section{ЗАКЛЮЧЕНИЕ}

Полученные данные показали, что у больных СД2 содержание остеогенных прогениторных клеток повышено, при том, что количество ЭПК, препятствующих развитию атеросклероза, достоверно снижено. Эти данные позволили предположить, что активация остеогенных прогениторных клеток играет важную роль в повреждении сосудистой стенки, развитии сосудистых осложнений при СД2, может способствовать атеросклеротической кальцификации и, возможно, влияет на увеличение частоты развития неблагоприятных сердечно-сосудистых событий у больных СД2.

Наши данные выявили, что процессы атеросклероза и кальцификации интимы являются взаимно отягощающими факторами, приводящими к прогрессированию СС3, особенно у пациентов с СД2. Наличие выраженного кальциноза сосудов при СД2 является неспецифическим маркером тяжелого поражения коронарных артерий. Полученные результаты подтверждают теорию клеточноопосредованного пути развития СК. У больных СД2 выявлена тесная корреляционная связь содержания CD34+OCN+-клеток с повышенной сосудистой кальцификацией, тяжелым многососудистым поражением коронарных артерий, что в совокупности может влиять на прогрессирование ССЗ в данной когорте пациентов.

\section{ДОПОЛНИТЕЛЬНАЯ ИНФОРМАЦИЯ}

Финансирование работы. Финансирование исследования проводилось в рамках государственного задания Министерства здравоохранения РФ по теме НИР: «Выявление иммуногистохимических и патоморфологических механизмов поражения сосудистой стенки и кальцификации артерий, а также механизмов развития микрососудистой ишемии у больных сахарным диабетом».

Конфликт интересов. Авторы декларируют отсутствие двойственности (конфликта) интересов, связанных с данной рукописью.

Участие авторов. Дедов И.И., Шестакова М.В., Калашников В.Ю., Смирнова О.М. - концепция и дизайн исследования, редактирование и окончательное утверждение статьи; Степанова С.М. - выполнение лабораторных исследований, проверка и правка текста рукописи; Захаров А.С. - проведение рентгенэндоваскулярных вмешательств; Мичурова М.С. - сбор клинического материала, статистическая обработка результатов исследования, интерпретация результатов, написание текста рукописи. 


\section{СПИСОК ЛИТЕРАТУРЫ | REFERENCES}

1. Low Wang CC, Hess CN, Hiatt WR, Goldfine AB. Clinical Update: Cardiovascular Disease in Diabetes Mellitus. Circulation. 2016;133(24):2459-2502. doi: 10.1161/CIRCULATIONAHA.116.022194

2. Abedin M, Tintut Y, Demer LL. Vascular Calcification. Arterioscler Thromb Vasc Biol. 2004;24(7):1161-1170. doi: 10.1161/01. ATV.0000133194.94939.42

3. Lanzer P, Boehm M, Sorribas V, et al. Medial vascular calcification revisited: review and perspectives. Eur Heart J. 2014;35(23):1515-1525. doi: 10.1093/eurheartj/ehu163

4. Eghbali-Fatourechi GZ, Lamsam J, Fraser D, Nagel D, Riggs BL, Khosla S. Circulating Osteoblast-Lineage Cells in Humans. N Engl J Med. 2005;352(19):1959-1966. doi: 10.1056/NEJMoa044264

5. Fadini GP, Albiero M, Menegazzo L, et al. Widespread Increase in Myeloid Calcifying Cells Contributes to Ectopic Vascular Calcification in Type 2 Diabetes. Circ Res. 2011;108(9):1112-1121. doi: $10.1161 /$ CIRCRESAHA. 110.234088

6. Egan KP, Kim J-H, Mohler ER, Pignolo RJ. Role for Circulating Osteogenic Precursor Cells in Aortic Valvular Disease. Arterioscler Thromb Vasc Biol. 201 1;31 (12):2965-2971. doi: 10.1161/ATVBAHA. 111.234724

7. Wylie-Sears J, Aikawa E, Levine RA, Yang J-H, Bischoff J. Mitral Valve Endothelial Cells With Osteogenic Differentiation Potential. Arterioscler Thromb Vasc Biol. 2011;31(3):598-607. doi: 10.1161/ATVBAHA.110.216184

8. Gössl M, Mödder UI, Atkinson EJ, Lerman A, Khosla S. Osteocalcin Expression by Circulating Endothelial Progenitor Cells in Patients With Coronary Atherosclerosis. J Am Coll Cardiol. 2008;52(16):1314-1325. doi: 10.1016/j.jacc.2008.07.019

9. Fadini GP. A reappraisal of the role of circulating (progenitor) cells in the pathobiology of diabetic complications. Diabetologia. 2014;57(1):4-15. doi: 10.1007/s00125-013-3087-6

10. Han Y, Hsieh FH. Osteogenic Differentiation of Late-Outgrowth CD45-Negative Endothelial Progenitor Cells. J Vasc Res. 2014;51(5):369-375. doi: 10.1159/000368929

11. Lee J-H, Hah Y-S, Cho H-Y, et al. Human Umbilical Cord Blood-Derived CD34-Positive Endothelial Progenitor Cells Stimulate Osteoblastic Differentiation of Cultured Human Periosteal-Derived Osteoblasts. Tissue Eng Part A. 2014;20(5-6):940-953. doi: 10.1089/ten.tea.2013.0329

12. Criqui $\mathrm{MH}$, Denenberg JO, Ix JH, et al. Calcium Density of Coronary Artery Plaque and Risk of Incident Cardiovascular Events. JAMA. 2014;311(3):271-278. doi: 10.1001/jama.2013.282535

13. Дедов И.И., Шестакова М.В., Майоров А.Ю., и др. Алгоритмы специализированной медицинской помощи больным сахар- ным диабетом / Под редакцией И.И. Дедова, М.В. Шестаковой, А.Ю. Майорова. - 8-й выпуск // Сахарный диабет. - 2017. - Т.20. №1S. - C.1-121. Dedov II, Shestakova MV, Mayorov AY, et al. Standards of specialized diabetes care. Edited by Dedov II, Shestakova MV, Mayorov AY. 8th edition. Diabetes mellitus. 2017;20(1S):1-121. (InRuss.)] doi: 10.14341/DM20171S8

14. Farooq V, Head SJ, Kappetein AP, Serruys PW. Widening clinical applications of the SYNTAX Score. Heart. 2014;100(4):276-287. doi: 10.1136/heartjnl-2013-304273

15. Rusnak J, Behnes M, Henzler T, et al. Comparative analysis of high-sensitivity cardiac troponin I and $\mathrm{T}$ for their association with coronary computed tomography-assessed calcium scoring represented by the Agatston score. Eur J Med Res. 2017;22(1):47. doi: 10.1186/s40001-017-0290-9

16. Shaw LJ, Giambrone AE, Blaha MJ, et al. Long-Term Prognosis After Coronary Artery Calcification Testing in Asymptomatic Patients. Ann Intern Med. 2015;163(1):14-21. doi: 10.7326/M14-0612

17. Fadini GP, Albiero M, Menegazzo L, et al. Procalcific Phenotypic Drift of Circulating Progenitor Cells in Type 2 Diabetes with Coronary Artery Disease. Exp Diabetes Res. 2012;2012:1-7. doi: $10.1155 / 2012 / 921685$

18. Aikawa E, Nahrendorf M, Figueiredo J-L, et al. Osteogenesis Associates With Inflammation in Early-Stage Atherosclerosis Evaluated by Molecular Imaging In Vivo. Circulation. 2007;1 16(24):2841-2850. doi: 10.1161/CIRCULATIONAHA.107.732867

19. Sage AP, Tintut $Y$, Demer LL. Regulatory mechanisms in vascular calcification. Nat Rev Cardiol. 2010;7(9):528-536 doi: 10.1038/nrcardio.2010.115

20. Kelly-Arnold A, Maldonado N, Laudier D, et al. Revised microcalcification hypothesis for fibrous cap rupture in human coronary arteries. Proc Natl Acad Sci. 2013;110(26):10741-10746. doi: 10.1073/pnas.1308814110

21. Vengrenyuk Y, Carlier S, Xanthos S, et al. A hypothesis for vulnerable plaque rupture due to stress-induced debonding around cellular microcalcifications in thin fibrous caps. Proc Natl Acad Sci. 2006;103(40):14678-14683. doi: 10.1073/pnas.0606310103

22. Игнатьев И.М., Челышев Ю.А., Заночкин А.В., и др. Кальцификация атеросклеротических бляшек и оценка их стабильности // Ангиология и сосудистая хирургия. - 2017. - Т.23. - №1 - С.13-20. [Ignatiev I.M., Chelyshev Yu.A., Zanochkin A.V., et al. Calcification of atherosclerotic plaques and assessment of their stability. Angiologiâ i sosudistaâ hirurgiâ. 2017;23(1):13-20. (In Russ.)]

\section{ИНФОРМАЦИЯ ОБ АВТОРАХ [AUTHORS INFO]}

* Мичурова Марина Сергеевна, н.с. [Marina S. Michurova, MD, research associate]; адрес: Pocсия, 117036, Москва, улица Дм. Ульянова, д.11 [address: 11 Dm. Ulyanova street, 117036 Moscow, Russia]; ORCID: http://orcid.org/0000-0003-1495-5847; eLibrary SPIN: 5655-2328; e-mail: m.michurova@yandex.ru

Калашников Виктор Юрьевич, д.м.н., профессор, член-корреспондент РAH [Victor Yu. Kalashnikov, MD, ScD, professor, corresponding member of the RAS]; ORCID: http://orcid.org/0000-0001-5573-0754; eLibrary SPIN: 5342-7253; e-mail: victor9368@gmail.com

Смирнова Ольга Михайловна, д.м.н., профессор [Olga M. Smirnova, MD, ScD, professor];

ORCID: http://orcid.org/0000-0003-3885-8988; eLibrary SPIN: 9742-8875; e-mail: dr_smr@mail.ru

Захаров Александр Сергеевич [Alexander S. Zakharov, MD]; ORCID: http://orcid.org/0000-0003-3179-8599; eLibrary SPIN: 7597-4979; e-mail: zakharovas@gmail.com

Степанова Светлана Михайловна [Svetlana M. Stepanova, MD]; ORCID: http://orcid.org/0000-0003-4238-0390; eLibrary SPIN: 5110-9922; e-mail: genetics2@yandex.ru

Шестакова Марина Владимировна, д.м.н., профессор, академик PAH [Marina V. Shestakova, MD, ScD, professor, academician of the RAS]; ORCID: http://orcid.org/0000-0003-3893-9972; eLibrary SPIN: 7584-7015; e-mail: nephro@endocrincentr.ru

Дедов Иван Иванович, д.м.н., профессор, академик PAH [Ivan I. Dedov, MD, ScD, professor, academician of the RAS]; ORCID: http://orcid.org/0000-0002-8175-7886; eLibrary SPIN: 5873-2280; e-mail: dedov@endocrincentr.ru 


\section{ЦИТИРОВАТЬ:}

Мичурова М.С., Калашников В.Ю., Смирнова О.М., Степанова С.М., Захаров А.С., Шестакова М.В., Дедов И.И. Значение циркулирующих прогениторных клеток с остеогенной активностью в развитии атеросклероза у больных сахарным диабетом 2 типа // Ожирение и метаболизм. - 2019. - Т.16. — №1. - C. 62-69. doi: 10.14341/omet9831

\section{TO CITE THIS ARTICLE:}

Michurova MS, Kalashnikov VYu, Smirnova OM, Stepanova SM, Zakharov AS, Shestakova MV, Dedov II. The significance of circulating progenitor cells with osteogenic activity in the atherosclerosis development in patients with type 2 diabetes mellitus. Obesity and metabolism. 2019;16(1):62-69. doi: 10.14341/omet9831 